\title{
Adherence to daily dietary and activity goals set within a Māori and Pacific weight loss competition
}

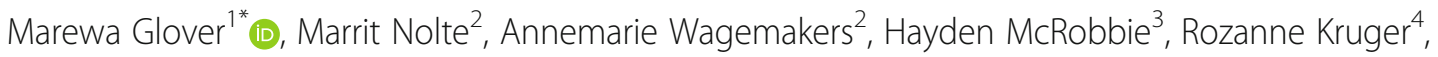
Bernhard H. Breier ${ }^{4}$, Jane Stephen ${ }^{1}$, Mafi Funaki-Tahifote ${ }^{5}$ and Mathu Shanthakumar ${ }^{6}$

\begin{abstract}
Background: New Zealand Pacific and Māori populations measure disproportionately high on the international body mass index (BMI). Information is needed on what behavioural weight loss goals to recommend and how to attract and retain them in interventions. Our team weight loss competition trial for participants with a BMI $\geq 30$ used cash prizes to incentivise completion of nine daily behaviour goals. This paper evaluates the theoretical merit of and adherence to these goals.

Methods: A qualitative component evaluation methodology was used. Trial data on team activity, demographics and anthropometric outcome data were extracted to determine frequency of daily goal completion by teams throughout the competition and to describe participant characteristics. T-tests were used to compare completion rates of the challenges, challenge completion by day of week and between weekdays and weekends. To examine adherence to the daily challenge activity over 24 weeks the total amount of completed challenges adjusted for number of active teams was plotted by week. A Body Shape Index (ABSI) was used to determine individual anthropometric change from baseline to 8, 16 and 24 weeks. Program documents were analysed to identify barriers to adherence and retention of participants.

Results: Of 19 teams $(N=130)$ who began only five teams performed daily goals across the whole 24 weeks. Adherence was highest during the first 8 weeks. No difference in performance between goals was found suggesting they were equally viable, though tasks worth less points were performed more frequently. Goal completion was higher on weekdays. The behaviour goals appeared to have theoretical merit in that more members of high performing teams experienced a positive change in their ABSI.

Conclusions: Incentives offer a promising strategy for encouraging retention in weight loss interventions. This study suggests that participants in a competition will perform incentivised tasks. The findings however, are limited by missing data and high drop out of individuals and whole teams. Further research is needed on how to increase retention.
\end{abstract}

Keywords: Obesity prevention, Weight loss competition, Lifestyle challenges, Indigenous

\footnotetext{
* Correspondence: marewaglover@xtra.co.nz; m.glover@coreiss.com

${ }^{1}$ School of Health Sciences, College of Health, Massey University, PO Box

89186, Torbay, Auckland 0742, New Zealand

Full list of author information is available at the end of the article
}

(c) The Author(s). 2019 Open Access This article is distributed under the terms of the Creative Commons Attribution 4.0 International License (http://creativecommons.org/licenses/by/4.0/), which permits unrestricted use, distribution, and reproduction in any medium, provided you give appropriate credit to the original author(s) and the source, provide a link to the Creative Commons license, and indicate if changes were made. The Creative Commons Public Domain Dedication waiver (http://creativecommons.org/publicdomain/zero/1.0/) applies to the data made available in this article, unless otherwise stated. 


\section{Background}

Rates of obesity (having a BMI of 30 or over) are increasing worldwide [1]. New Zealand (NZ) has a high prevalence of obesity which varies by deprivation level and ethnicity [2]. NZ resident Pacific and Mãori (indigenous) people, who are over-represented among the most deprived, have disproportionately high rates of obesity (68.7 and $50.2 \%$ respectively) compared to the European population (30.5\%) [3]. These ethnic inequalities are reflected in excess incidence and mortality rates for Pacific and Māori populations in several obesity-related cancers [4] and greater prevalence of diabetes $(11.4 \%$ for Pacific males and $11.6 \%$ for females; 8.2\% among Māori men and 7\% for females; versus 3\% for NZ European/Other males and 2.2\% for females) [5]. Cardiovascular disease (CVD) is experienced disproportionately also. In 2012-2014, Mãori people were more than 1.5 times as likely as non-Māori people to be hospitalised for CVD [6].

Changing and controlling dietary behaviours and increasing physical activity [7-9], is the primary lifestyle treatment recommended for obesity [10]. Behavioural therapy, including techniques such as self-monitoring, stimulus control, goal-setting, problem-solving, relapse prevention, cognitive restructuring and motivation enhancement are believed to improve adherence to behavioural change interventions [11].

Although mortality associated with obesity has declined over the last three decades in NZ, the rate of decline has been slower among Māori and Pacific Island populations $[12,13]$. Evidence is needed on how best to engage and retain Māori and Pacific people in weight change programmes, and what behavioural changes are effective and sustainable $[14,15]$.

This paper assesses the daily behavioural goals set for participants of a 24 week Pacific and Māori team weight loss competition. The Ka Mau Te Wehi (a Mãori saying that means Awesome!) competition was designed to trigger sustainable changes that could result in reduced CVD and type 2 diabetes (T2D) risk among adults with a BMI of 30 or over. Unlike other weight loss competitions [16, 17] WEHI participants earned points not just for anthropometric changes, but for completion of daily dietary and physical activity goals (challenges). The aim was to examine adherence to the challenges throughout the competition by asking how many and which challenges were performed. We also sought to assess the theoretical merit of the daily challenges by investigating if there was any indication that completion of the challenges contributed to the desired anthropometric changes.

\section{The WEHI trial}

The rationale and method for the WEHI trial is fully described elsewhere [18]. Briefly, Māori and Pacific adults
16 years and over with a BMI of 30 or more were invited to participate in one of three (a Māori urban, a Māori rural and a Pacific urban) 24 week long weight loss competitions between September 2016 to February 2017. Each region was to recruit seven intervention teams of 7 people $(N=149)$ and an equal number of individuals to form a control group. Data from questionnaires and measurements was collected during September 2016 December 2017 at baseline, 8, 16, 24 and 48 weeks from the intervention group and baseline and 24 weeks from the control group. Data collection at 48 weeks from the control participants was abandoned due to insufficient enrolment of participants. Weight and waist circumference measurements (WC) were performed by research assistants and questions on nutrition literacy and behaviour, physical activity, food security and body image were self-completed. In each competition area a regional health provider was contracted and trained to recruit participants, collect data and co-ordinate the competition. They distributed recruitment notices and gave presentations through their existing networks. People who were pregnant, breastfeeding or using nicotine (due to its association with weight control [19]) were excluded.

Te Whare Tapa Wha (the four-sided house), a Māori holistic model of health underpinned the WEHI program theory (Fig. 1). Program theory explains how the elements of an intervention are expected to work and how it is expected to achieve the desired results [20]. Te Whare Tapa Wha posits that wellbeing is determined by balance across several realms: te taha tinana (physical/ bodily health), te taha hinengaro (the mental realm of knowledge and emotions), te taha whānau (one's environment including the quality of family and social relationships and social belonging) and te taha wairua (the spiritual realm). These proximal determinants of health are impacted on by the wider socio-historical-political environmental context (te ao tūroa - the long-standing environment). Pacific cultures have similar holistic health models, such as the Fonofale model, which emphasises the centrality of family and culture [21].

The four intervention components based on this theory were: 1) support from both the health provider and team members (te taha whanau), 2) within region inter-team competition with incentives (spot and cash prizes) for completing (te taha hinengaro), 3) daily and weekly behavioural challenges (te taha tinana), and 4) internet delivered education and support (te taha hinengaro). Programme resources were provided to enable individual and team activity tracking (individual activity diary (Fig. 2) and a team activity summary sheet) and reporting (via the website). Each team was given a set of bathroom scales to use as a motivational tool at group meetings if they wanted to. Each participant received a fridge magnet listing the daily challenges as a mnemonic 


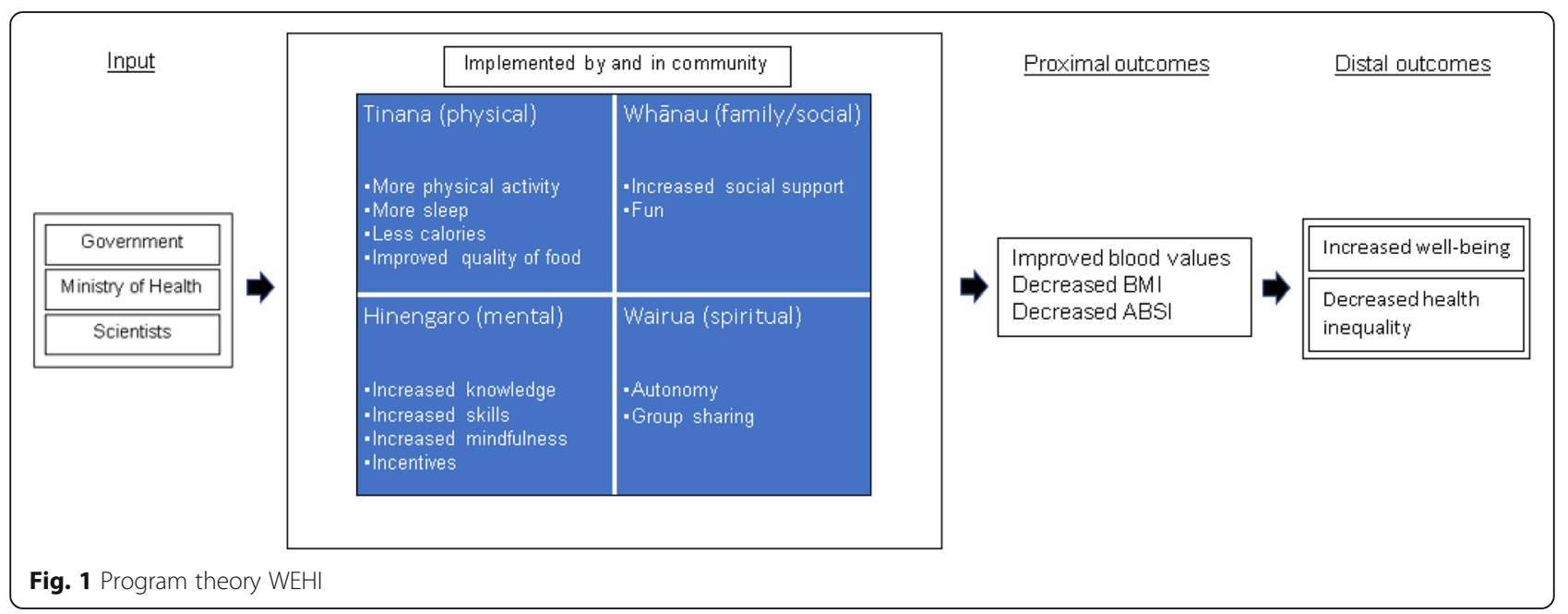

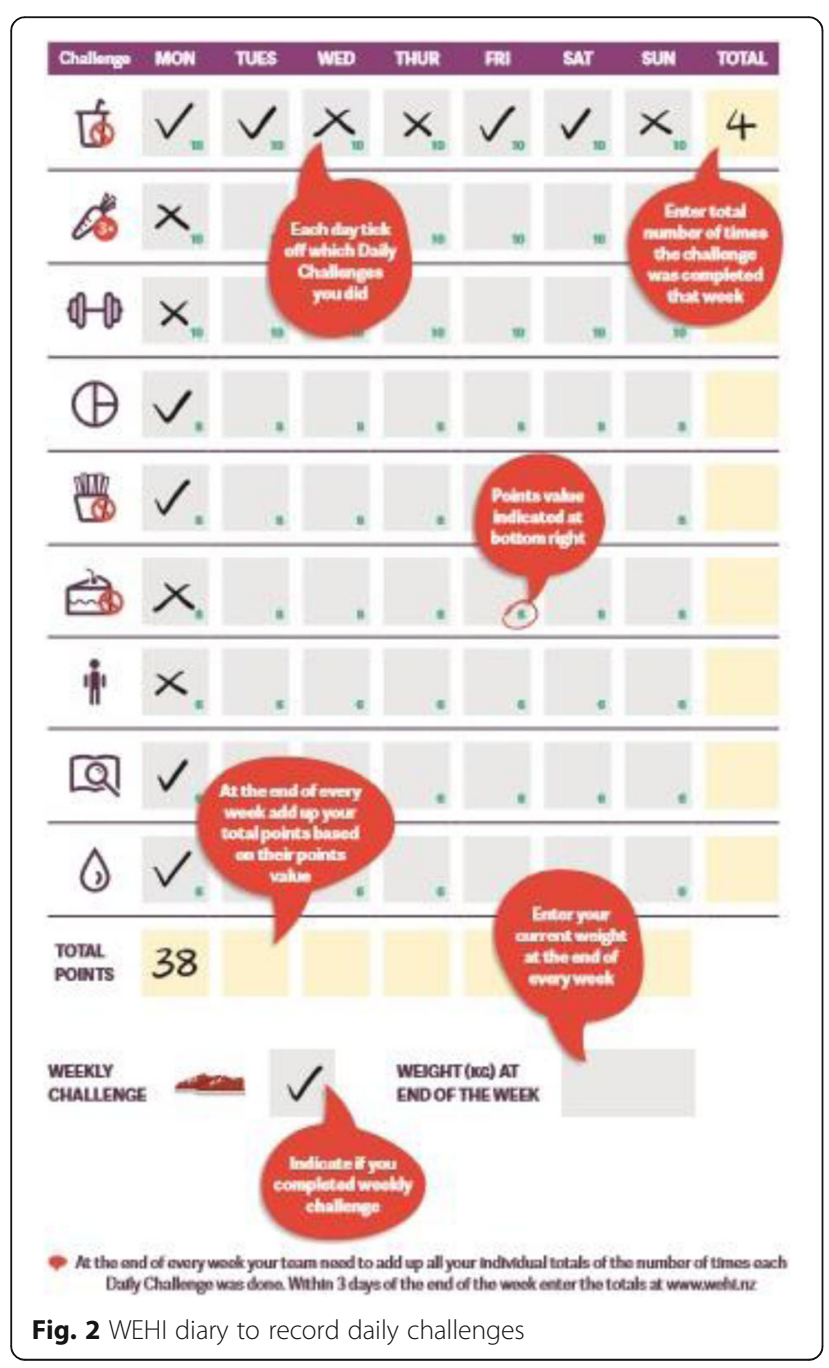

device. At the end of week 8 and 16 the leading team in each competition, based upon team members' weight and WC loss and highest team activity score (Fig. 3), won \$NZ1000 (\$US678, €587). The final prize at 24 weeks was $\$ N Z 3000$ per region. The prize went to the team's nominated charity.

\section{Daily challenges}

The WEHI daily challenges emerged from a literature review to identify behavioural changes associated with weight loss. The NZ Eating and Activity Guidelines for Adults [22] were given priority to ensure consistency with Ministry of Health goals. An initial list of goals were then ranked by seven of the WEHI researchers, who have expertise in obesity prevention, nutrition, physical activity and behavioural change. The ranking criteria were 1) efficacy for achieving weight loss, 2) effectiveness for reducing risk of CVD and T2D but also 3) stimulating positive behaviour change instead of restricting behaviour. Several additional behavioural goals were suggested, such as eating with others. A second expanded list was ranked as above, then refined to ensure a final list of measurable activities that participants could sustain and that addressed a range of determinants of obesity. In addition, challenges had to be simple to understand and activities most participants could do. For example, though an important negative influence on weight control, refraining from alcohol was excluded because Pacific women are less likely to consume alcohol [23]. The researchers discussed the ranked challenges, reducing the list to nine which were assigned a points value proportionate to their importance for weight reduction. Assigning more points to the more important challenges was intended to motivate participants to give priority to those challenges. The final list of daily challenges (Table 1) mainly focused on te taha tinana, including physical activity and dietary changes, 


\begin{tabular}{|c|c|c|c|c|}
\hline $\begin{array}{l}X \text { (number team } \\
\text { members lost } \geq 4 \mathrm{kgs} \\
\text { overprevious } 8 \\
\text { weeks) }\end{array}$ & + & $\begin{array}{l}Y \text { (number te am members } \\
\text { lost } \geq 3 \mathrm{cms} \text { waist } \\
\text { circumference over } \\
\text { previous } 8 \text { weeks) }\end{array}$ & + & $\begin{array}{l}Z \text { (Team's ranking on competition leader } \\
\text { board reflecting reported completed } \\
\text { challenges over previous } 8 \text { weeks, with } \\
\text { highest rank }=7 \text {, lowest }=1 \text { ) }\end{array}$ \\
\hline
\end{tabular}

Fig. 3 Formula used to calculate team progress at $8,16 \& 24$ weeks

Table 1 Daily challenges, ranking, description and rationale

\begin{tabular}{|c|c|c|c|}
\hline $\begin{array}{l}\text { Daily } \\
\text { Challenge }\end{array}$ & $\begin{array}{l}\text { Points } \\
\text { value }\end{array}$ & Description & Rationale \\
\hline $\begin{array}{l}\text { Sugar- } \\
\text { free Drink } \\
\text { Day }\end{array}$ & 10 & $\begin{array}{l}\text { A day without drinking sugar-sweetened soft drinks or fruit } \\
\text { juices or cordials. This included not adding sugar to tea or } \\
\text { coffee. }\end{array}$ & $\begin{array}{l}\text { One of the major sources of added sugars are non-alcoholic } \\
\text { beverages, such as sugar-added carbonated drinks and fruit } \\
\text { juices [22]. According to the 2008/09 New Zealand Adult Nutri- } \\
\text { tion Survey, 35.5\% of Māori adults and 39\% of NZ Pacific adults } \\
\text { have sugary drinks three or more times each week [56]. The } \\
\text { Ministry of Health Nutrition Guidelines recommend limiting con- } \\
\text { sumption of sugar-added drinks to less than once a week [22] }\end{array}$ \\
\hline
\end{tabular}

3+ Vege 10 A day when at least 3 servings of vegetables were consumed. Day

\begin{tabular}{|c|c|c|}
\hline $\begin{array}{l}\text { Exercise } \\
\text { Day }\end{array}$ & 10 & $\begin{array}{l}\text { A day when at least half an hour continuous walking or } \mathrm{m} \\
\text { strenuous exercise was completed. }\end{array}$ \\
\hline $\begin{array}{l}1 / 4^{1} / 4^{1} / 2 \\
\text { Dinner }\end{array}$ & 8 & $\begin{array}{l}\text { A day when the main meal is made up of } 1 / 2 \text { vegetables, } 1 / 2 \\
\text { protein and } 1 / 4 \text { carbohydrates. }\end{array}$ \\
\hline
\end{tabular}

protein and $1 / 4$ carbohydrates.

Day

Fast \& $\quad 8 \quad$ A day without fast or fried food.

Fried-free

Day

Sweet 8

Treat-free

Day

Stand Up 6

Day

Water 6

First Day
A day without eating sugar-sweetened biscuits, cakes, lollies, chocolate or puddings.

A day when long periods of sitting down are broken up by standing for at least a minute and this is done at least 3 times (once in the morning, once in the afternoon and once in the evening).

A day of drinking a glass of water no more than 5 min before eating each of your 3 main meals (breakfast, lunch \& dinner).
Build Me 6 Up Day
A day when at least 10 continuous minutes was spent focused on learning about or practising a new behaviour that will reduce stress, improve sleep quality or improve knowledge of nutrition. Visiting the WEHI website, reading the Tip of the Day and posting on the team page can count towards this.
Replacing high density foods with vegetables can help prevent excess weight gain since they are low in energy [57] In addition, this decreases the risk of non-communicable diseases such as stroke and some types of cancer [58, 59]. For this reason, it is recommended that New Zealanders consume at least three servings of vegetables per day [22].

A low amount of physical exercise has been proposed as a main contributor to obesity [60]. It has been suggested that increasing physical activity may reduce obesity [61, 62]

Healthy eating patterns involve eating a range of foods from four food groups: fruits and vegetables, grain foods, diary and legumes, chicken, nuts or red meat [22]. It is recommended that half of the meal consists of non-starchy vegetables because these are lower in total energy and contain a lot of vitamins and minerals. One quarter of the meal should consist of carbohydrates such as potato or kumara (sweet potato) and the last quarter should be protein-rich products [63].

Fast food products are usually high in calories [64]. Reducing the intake of saturated fat or replacing it by unsaturated fats is linked to a reduced risk of CVD [65]. Reduction in the intake of fast and fried foods, which are often deep-fried and high in saturated fats, is recommended $[66,67]$.

The intake of added sugars is linked to excess weight gain. The WHO recommends lowering the intake to less than $10 \%$ of the total energy intake $[22,68]$.

Over the last few decades, the time spent sitting has increased among NZ adults [69]. There are several reasons for this, including increased use of technology, and the built environment and transport being increasingly structured around sitting [70]. Taking regular breaks to stand and move around has been recommended to counter this [71].

This behaviour was intended to prompt mindfulness. Kabat-Zinn defines mindfulness as: 'awareness that emerges through paying attention on purpose, in the present moment, and nonjudgmentally to the unfolding of experience moment by moment' [72]. It is proposed that mindfulness can be employed to increase awareness of what you are eating and slow down your eating. Mindfulness is associated with lower calorie intake and healthier food choices [73].

This challenge was included to encourage participants to visit the website where they could find extra information on losing weight via the Tip of the Day, which was a main source of educational information, motivational messages and suggestions for dealing with barriers to change. 
as well as te taha hinengaro activities that intended to change knowledge, habits and increase mindfulness.

The cumulative points earned per team per week were entered by the team into their WEHI web page. Requiring only cumulative team points was intended to reduce participant burden.

To protect the competitive element of the intervention and the value of the prize incentive, challenges were offered as a range of activities to choose from, rather than a pragmatic or sustainable plan that could be enacted fully every day. If the plan was too easy then too many teams could 'win', reducing the incentive value if the prize had to be divided among too many winning teams.

\section{Methods}

A qualitative component evaluation methodology was used to assess the viability of the WEHI daily challenges. Component evaluation focuses on a particular aspect of an intervention to test and validate a program's theory [24]. Of interest is whether or not the component was implemented as intended and adhered to and if so, whether the proximal outcomes aimed for could be detected and thus could indicate that the program theory was feasible [24, 25]. This then informs the process to test the generalisability of the program, that is, if the aspect under investigation is likely to work once transferred to other sites or providers [25].

Demographic and outcome data were drawn from the WEHI trial data to calculate frequencies and describe participant characteristics. Program documents were analysed to identify barriers to adherence and retention of participants. Document analysis is commonly used in program evaluations to corroborate or help explain quantitative results [26].

\section{Data analysis}

Team activity data was downloaded from the website and demographic and anthropometric data was extracted from the WEHI trial database and entered into Excel [27]. The daily challenge data were used to calculate descriptive statistics and frequency counts of daily challenge activity. T-tests were used to compare completion rates of the challenges, challenge completion by day of week and between weekdays and weekends. To examine adherence to the daily challenge activity over 24 weeks the total amount of completed challenges adjusted for number of active teams was plotted by week. Adjustment was done by dividing the total amount of completed challenges by the number of active teams each week. To examine the theoretical merit of the daily challenges we hypothesised that more members from teams with higher total points at 8, 16 and 24 weeks would experience positive anthropometric changes. We first compared the active teams on gender, age and baseline BMI to test for differences.

A Body Shape Index (ABSI), introduced in 2012, is a new body index that detects an association between body composition and all-cause mortality more reliably than BMI and WC [28]. ABSI (WC/(BMI $/ 3 \times$ height $\left.t^{1} / 2\right)$ ) [29] was used to determine individual anthropometric change from baseline to 8,16 and 24 weeks because participants were encouraged to exercise daily which could potentially increase muscle mass reducing detection of loss in body fat in the short-term even though risks may be reduced $[29,30]$. Anthropometric change over each of the three 8-week competition periods, was calculated by subtracting ABSI of the participant at the beginning of the 8-week period from ABSI at the end of that period. A positive difference suggested a reduction in WC or weight, whilst a negative difference indicated an increase. Individual ABSI difference was then plotted against the team's cumulative daily challenge score for each 8 week period. Scatterplots are often used as a first step to explore if a likely correlation exists between variables [31]. The most this exploratory method can do, however, is provide an indication of program theory feasibility. Tests for an association between adherence to daily challenges and anthropometric change were not possible because only cumulative team performance, not individual performance, of daily challenges was collected.

Using a deductive analysis approach [26] WEHI documents were searched for information on how the programme was implemented. Monthly reports from regional co-ordinators $(N=10)$, monthly reports to the funder $(N=4)$ and emails between the regional co-ordinators and the research team were identified as most useful. These were read to identify and categorise reported barriers to adherence and implementation.

\section{Results}

In total, 130 participants (17 teams of 7, 1 team of 6 and 1 team of 5) began the intervention. Participants were mainly female (82\%), $63 \%$ were Māori, $42 \%$ were aged $45-54$ years $(n=55)$. Half of the participants had some education beyond secondary school and most (79\%) were currently employed (Table 2). Mean BMI at baseline was $41.0\left(\mathrm{~kg} / \mathrm{m}^{2}\right)$ (range 30.3-59.4).

Adherence was highest during the first 8 weeks of the programme (Fig. 4). After that the reduction in total reported challenges reflects the drop out of participants and or whole teams. The number of active teams decreased from 19 active teams in the first week to five active teams at the end of the competition. Most of the Northland teams dropped out after 15 weeks. Five participants withdrew or dropped out due to pregnancy or personal commitments. After adjusting the reported 
Table 2 Demographics ( $n=130)$

\begin{tabular}{|c|c|c|c|}
\hline & Count & $\%$ & \\
\hline \multicolumn{4}{|l|}{ Ethnicity } \\
\hline Māori & 81 & $63 \%$ & \\
\hline Pacific & 46 & $35 \%$ & \\
\hline Pākehā & 3 & $2 \%$ & \\
\hline \multicolumn{4}{|l|}{ Age } \\
\hline Under 35 & 24 & $19 \%$ & \\
\hline $35-44$ & 26 & $20 \%$ & \\
\hline $45-54$ & 55 & $42 \%$ & \\
\hline $55-64$ & 21 & $16 \%$ & \\
\hline $65-74$ & 4 & $3 \%$ & \\
\hline \multicolumn{4}{|l|}{ Sex } \\
\hline Male & 23 & $18 \%$ & \\
\hline Female & 107 & $82 \%$ & \\
\hline \multicolumn{4}{|c|}{ Highest completed qualification } \\
\hline School & 52 & $40 \%$ & \\
\hline Post-school & 72 & $55 \%$ & \\
\hline Missing & 6 & $5 \%$ & \\
\hline \multicolumn{4}{|l|}{ Work situation } \\
\hline Working & 104 & $80 \%$ & \\
\hline Not working & 20 & $15 \%$ & \\
\hline \multirow[t]{2}{*}{ Missing } & 6 & $5 \%$ & \\
\hline & Mean & SD & Range \\
\hline Weight (kg) & 113.3 & 21.2 & $73.5-176.4$ \\
\hline Height (m) & 1.66 & 0.07 & $1.49-1.89$ \\
\hline Waist circumference $(\mathrm{cm})$ & 118.3 & 14.2 & $92.2-164$ \\
\hline BMI & 40.9 & 6.30 & $30.3-59.4$ \\
\hline
\end{tabular}

challenges for active teams, the drop off in completed challenges was less significant. Active teams reported a steady completion of daily challenges.

Proportion of daily challenges completed each week by team against a maximum of 441 if all team members performed every challenge every day of the week is shown in Fig. 5, 6, 7 (1 per region). Daily challenge activity fluctuated widely within teams. The highest standard deviation (SD) within a team per week was 185. Some teams did not complete any challenges for 1 week but did enter completed challenges the week after. Throughout the competition, the active teams earned on average $234(\min =150, \max =288)$ points for completing challenges per week. The winning teams in each region completed an average of 376 (Northland), 378 (Auckland) and 213 (Manawatu) challenges per week. In Northland and Auckland, the winning teams were quite steady in reporting challenges with no significant difference between them.

Stand Up Day was completed most frequently followed by Water First Day (Fig. 8). Exercise Day and Sweet Treat-free Day were performed the least. Regional co-ordinator reports noted that participants found the Exercise Day and Sweet Treat-free Day the hardest. The easiest challenges to perform were reportedly Stand Up Day and Sugar-free Drink Day. The lowest ranked challenges (worth 6 points each) were in total performed more frequently than the highest ranked challenges (worth 10 points each) though this difference was not significant $(p=0.2)$.

Challenges were more likely to be completed on weekdays than on weekends (Fig. 9), with significant

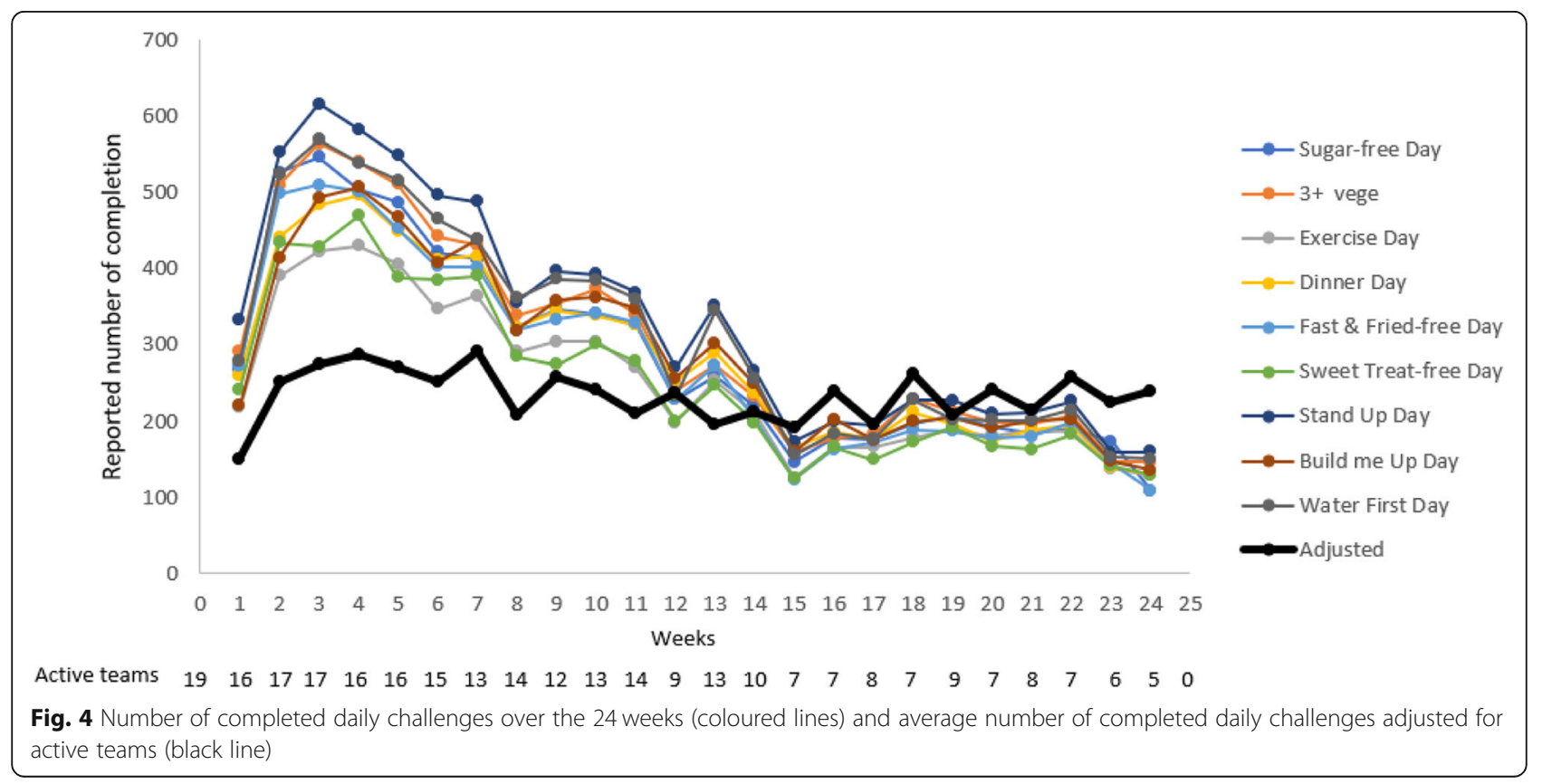




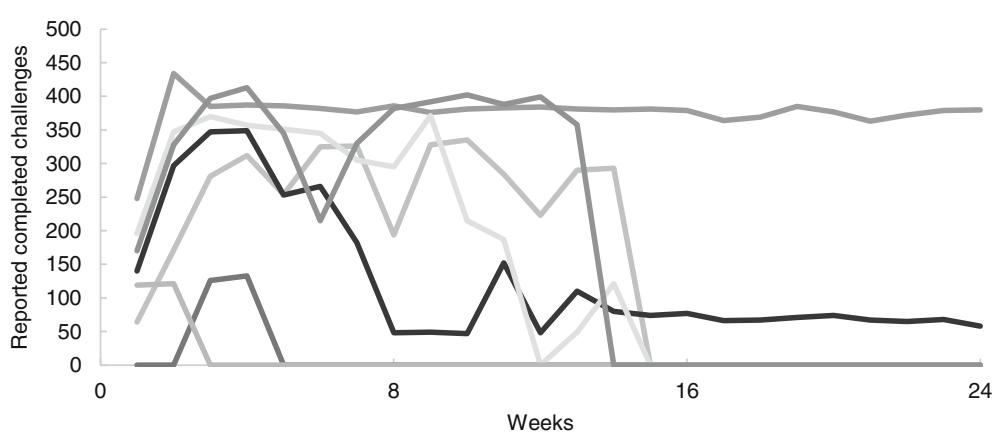

Fig. 5 Number of completed challenges per team per week (Northland) (maximum completion =441)

differences for the Sugar-free Drink Day $(p=0.00), 3+$ Vege Day $(p=0.006), 1 / 4 \frac{1}{1} 4^{1 / 2}$ Dinner Day $(p=0.002)$, Fast \& Fried-free Day $(p=0.004)$, Sweet Treat-free Day $(p=$ $0.000)$ and Stand Up Day $(p=0.018)$.

Reported barriers to adherence included physical injury, drop off in motivation, lack of social support and competing priorities. For example, one of the participants injured her ankle and was not able to exercise.

Figure 10 suggests that the higher the teams' total points, the more likely their members experienced a positive change in ABSI. This pattern was not obvious for weeks 8-16 and reversed for week 16-24 (data not shown) as the number of participants and active teams dropped off.

\section{Discussion}

This study evaluated the key behavioural component of a culturally-informed team weight loss competition by assessing reported team adherence to the daily challenges and the feasibility that performance of these might result in positive anthropometric changes. Prevalence of obesity-related disease is rising and the efficacy of interventions to reduce CVD/T2D risk factors such as obesity remains contested [32]. Meanwhile, health systems are under pressure to achieve efficiency gains [33]. Evaluations of programmes to assess if they were implemented as intended are important, however, they often omit validation of the behavioural change components against the program theory [24]. Assessing the integrity with which a program is implemented becomes less useful if the behavioural change component of a programme is ineffective.

Retention of participants in this trial was poor. However, high drop-out rates and decreasing adherence in weight loss interventions is common [34-36]. Adherence to the WEHI daily challenges decreased over time and drop out of teams past the first 8 weeks limited analysis. Only the five teams who won money at 8 or 16 weeks persisted to 24 weeks and only four of them provided full anthropometric and daily challenge completion data. Numerous barriers to retention were cited, such as, declining motivation, lack of social support, lack of time and lack of being able to prioritise involvement in the WEHI intervention. Most of the participants were employed. The required activity tracking, necessity to compile team activity data each week and enter it online compounded what was already an intensive intervention requiring participants to plan for and complete up to nine challenges each day. Participant burden may have been too high for all but the winning teams leading to reduced adherence in reporting and subsequent loss of motivation to perform the challenges [37]. Adherence

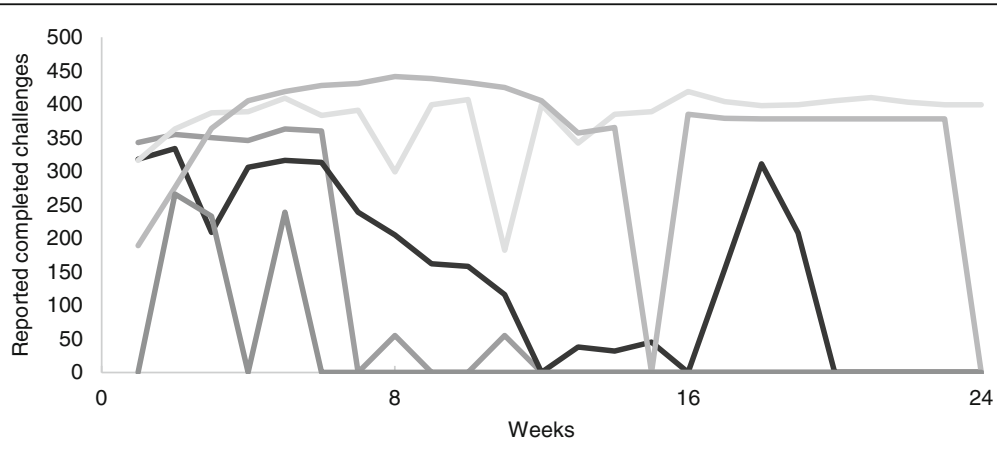

Fig. 6 Number of completed challenges per team per week (Auckland (Pacific)) (maximum completion = 441) 


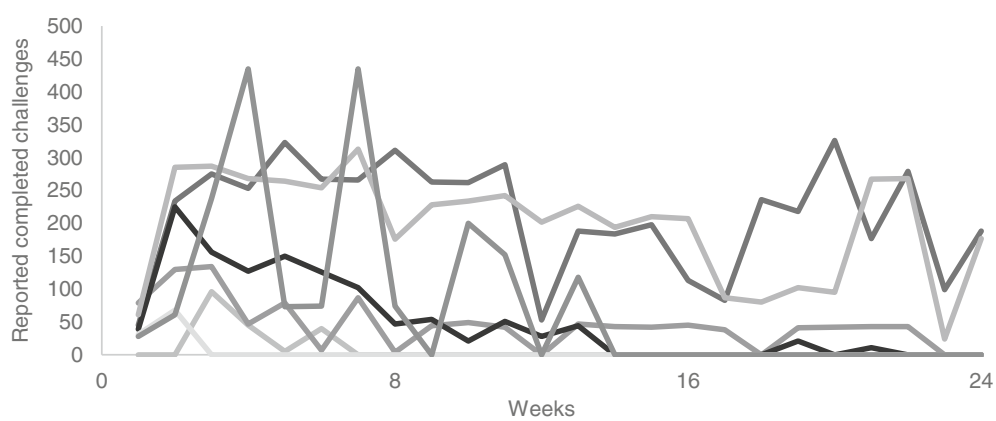

Fig. 7 Number of completed challenges per team per week (Manawatu) (maximum completion =441)

was significantly lower on weekends. Other studies have reported a similar pattern, for instance, American adults reportedly consume more fat in the weekend [38]; meal sizes were also larger on the weekend [39] and rates of physical activity decreased [40]. Church commitments, which are an important part of Pacific culture [41], could have contributed to reduced adherence during the weekend for Pacific participants. Further research is needed to determine the attitudes and barriers to weight loss plan enactment on weekends. It has been suggested that fun leisure-time physical activities (e.g. swimming, walking) are preferred over activity integrated into daily life (e.g. standing up more or taking the stairs), or health-related fitness activity (e.g. strength-building gym classes) [34]. Contrary to this, our easy standing challenge was performed most frequently. Future weight loss competitions should differentially incentivise week days and weekend adherence, and fun leisure-time activity.

\section{Boosting motivation}

Reduced motivation was reported as another barrier to adherence. Literature suggests that people with obesity typically engage less in physical activity and have greater motivation to avoid exercise [42]. Embedding flexibility as to which behaviours participants choose to perform has however been found to increase plan enactment [34]. Motivation appears influential in that highly specified action plans can be effective when individuals are highly motivated [34]. It was a limitation that motivation was not measured in the WEHI trial. On the other hand, WEHI participants were recruited from a general population versus a clinical population advised to seek treatment for obesity and thus were likely to be more motivated. To boost motivation, WEHI used competition and incentives.

Financial incentives have been found to be motivating [43] but as might be the case in this study, the converse could also be true that once the prize has gone to others or the chance of winning seems impossible due to high points achieved by leading teams or when treatment expectations are too high, motivation to continue wanes [43]. Retention might be improved if all participants and or their team 'wins' some of the prize pool, for example, proportionate to their team points. Proportioning reward to effort has been successfully used before in weight loss competitions [44]. Further studies are needed to identify the optimal structure for rewarding progress in weight loss competitions.

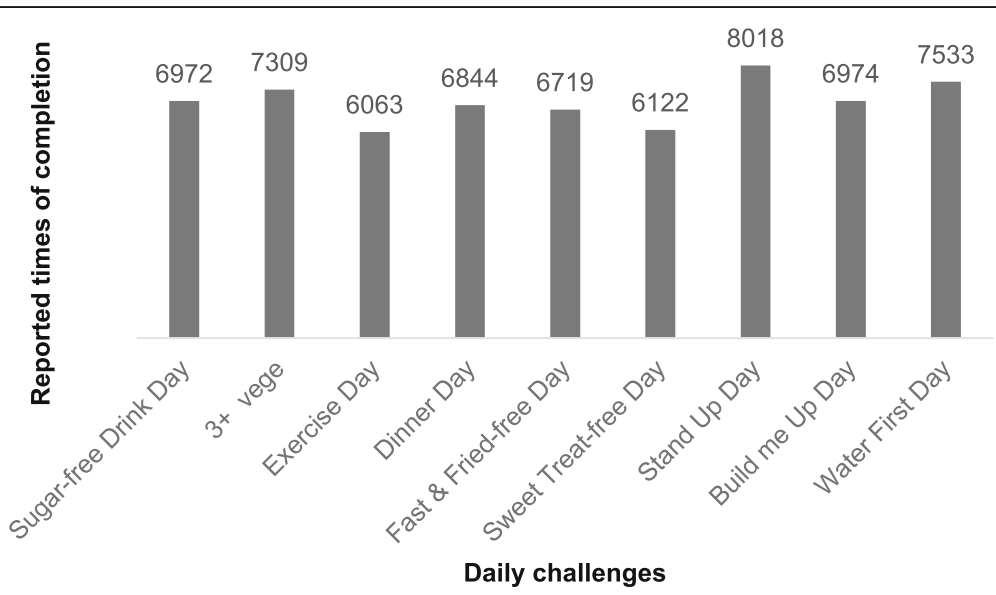

Fig. 8 Frequency of daily challenges (maximum completion $=22,344$ ) 


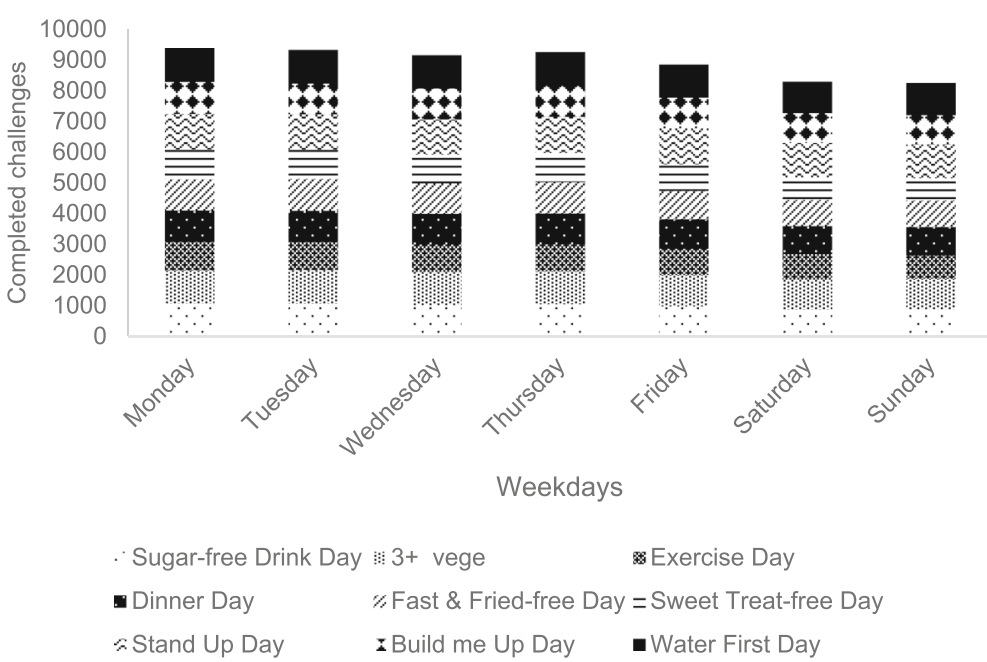

Fig. 9 Reported daily challenges per day of the week

\section{The daily challenges had merit}

Active teams submitted a large amount of data enabling a detailed look at the viability of the daily challenges. For the teams that completed the competition, the nine challenges appeared to be equally viable. The differential points value of the challenges was intended to motivate performance of the higher ranked behaviours. A greater differential in points should be employed to encourage greater adherence to the more important behaviour goals. It should be noted however, that the five highest performing teams, who won money at early progress points in the competition, reported very high team completion of all nine challenges most days of the week and for most of the competition. This could have undermined the detection of viability differences between the nine challenges. Teams aiming for exceptionally high challenge completion rate potentially created problems that undermined the effectiveness of the intervention.
Firstly, unfeasible or non-viable behavioural change plans are hard to sustain [43] and can lead to reduced progress [35], loss of self-efficacy and delayed or curtailed motivation to try again [45]. It is highly likely that the absence of progress de-motivated participants of non-winning teams [35]. Additionally, for weight loss interventions to be effective, prescribed goals need to be acceptable to participants, able to be completed by them and congruent with contextual demands in their lives [34]. Proportional reward for effort could mitigate these reasons for withdrawal.

The lack of individual daily challenge data and the drop out of teams prevented testing for a correlation between daily challenge completion rate and intended anthropometric change. A simplistic examination of the data supported the idea that higher completion of daily challenges would plausibly lead to a positive change in ABSI, but this was only observed at the end of the first

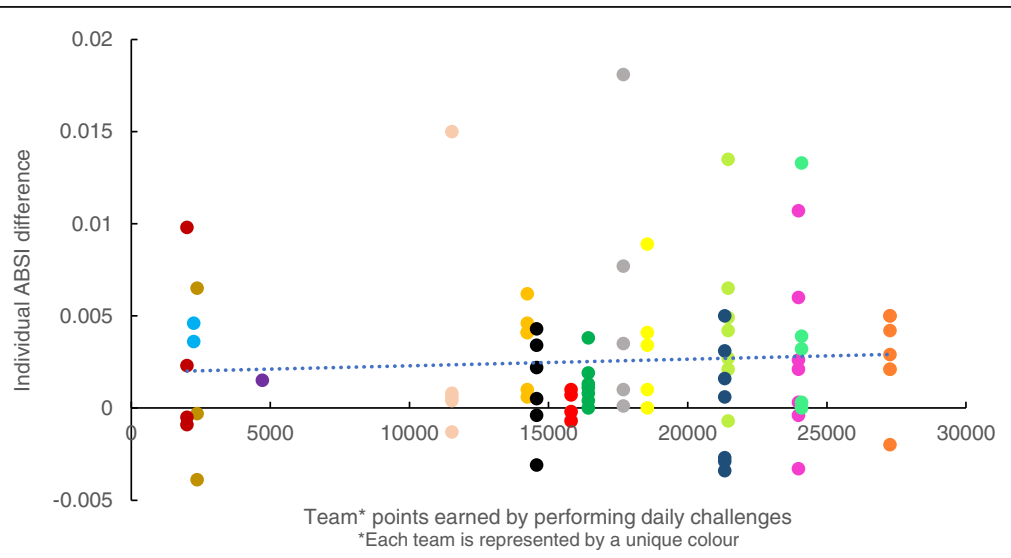

Fig. 10 Individual difference in ABSI plotted against team points achieved in week 0-8 $(n=85)$. Included participants had full data on weight, waist, height at baseline and 8 weeks and were part of a team which earned a significant amount of team points during this period 
8 weeks during which retention and adherence was highest. The daily behavioural goals were based on weight loss intervention literature and thus it makes sense that high adherence repeated over time should assist weight and WC loss. For example, the look AHEAD study, an 8 year weight loss intervention with 5145 obese adult participants, found that weight-maintenance activities such as higher levels of physical activity and reduced calorie intake were associated with increased weight loss [46]. Additionally, other literature supports that better attendance and completion is associated with weight loss outcomes. Carels et al. recruited 44 obese women to participate in a 6-month weight loss competition increasing physical activity and decreasing energy and fat intake [47]. They found a significant relationship between poor attendance and weight loss $(P<0.01)$. The greater positive anthropometric change indicated among team members in the highest performing teams, coupled with the apparent viability of the daily challenges and that high adherence and retention was achieved for teams with a high probability of winning a substantial cash prize suggests that WEHI is likely to be theoretically sound and is thus worthy of further development and testing with a larger sample size. Further evaluation assessing implementation and the barriers to adherence and retention is also warranted.

\section{Limitations and strengths}

There were several limitations to this study. First, the drop out of participants and teams limited the amount of data available for analysis and weakened the power to test for differences and relationships. A major contributor to the drop out was that the trial ran through the NZ summer Christmas/New Year holiday period (competition weeks 16-19 for Northland and Manawatu, and weeks 12-15 for Auckland). In NZ, community health organisations typically close down over this period. This most likely contributed to the loss of momentum and subsequent lack of interest in restarting after the holiday period. Running weight loss research or interventions through an extended holiday period is not pragmatic. Apart from this timing error, lack of motivation was given as an explanation for poor adherence and high drop-out. It is a limitation of the study that motivation to lose weight was not measured. Further research is needed on the role of motivation, and how to sustain motivation, in weight loss competitions. A significant limitation was that individual challenge completion data was not collected limiting the analyses that could be done. Only cumulative team completion was data was requested to reduce participant burden. The document analysis suggested that WEHI was experienced as requiring a significant and often prohibitive amount of time. Further work is needed to identify ways to reduce participant burden while also gathering sufficient information to enable robust evaluation. Phone based apps using push notifications to request data should be explored with internet and app literate groups [48].

A further limitation was that WEHI relied on self-reported activity which is vulnerable to social desirability bias, that is, participants would have been inclined to over-report completion of goals [49]. There is a higher risk of this occurring when incentives are involved [50]. This may have been moderated in WEHI because the cash prize went to a charity chosen by the winning team rather than to team members. On the other hand, participants could also have not reported their data because the burden was too high or they forgot about it. Self-report is supported by the literature however as it is a proven way to facilitate an individual's awareness of their behaviour which facilitates weight loss $[51,52]$. WEHI did not rely on self-report of anthropometric measurements, which was a strength but different researchers and regional co-ordinators conducted the measurements in the different regions. Requiring participants to attend 'weigh-ins' increased participant burden and likely contributed to missing data.

It is a strength that the study focused on people with a BMI of 30 and over. Motivation to change dietary and activity levels varies by risk status and obesity class [42]. Different interventions, varying in intensity and messages are likely to be needed depending on the motivation to change. The WEHI daily challenges were sufficiently flexible to allow for this variation between team members. The flexibility to form their own teams with family and friends is another strength since social support is positively related to weight loss [53]. The use of flexibility and the team environment are also supported by Deci \& Ryans self-determination theory, representing autonomy and relatedness [54]. The third component of self-determination theory, competence, is reinforced by points. Participants were predominantly females and employed limiting extrapolation of the findings to males and lower socio-economic or unemployed people who are obese. It is a strength that the study focused on a high risk indigenous group and a minority migrant population who have among the highest rates of obesity in the world.

\section{Conclusion}

To our knowledge this is one of the first studies trialling a team-based competition with a high CVD/T2D risk indigenous and Pacific population. The high recruitment rate and retention of at least the teams who received incentives supports that team competition is an attractive health promotion strategy to prompt a focus on weight loss for Māori and Pacific participants. Further research to determine the optimal incentive structure, such as 
proportioning reward to effort, to boost adherence to behavioural change goals whilst also retaining more teams for a longer term is needed.

Many health systems grappling with rising obesity rates are looking for simple effective weight loss messages that can be given to individuals, delivered to groups and their communities. As both a community based and internet-delivered programme, WEHI could be scaled up to assist people to lose weight and thus reduce CVD and T2D risk delivering population health benefits. This study suggests that a team based, culturally grounded approach was attractive to a high risk group and that the key behavioural change component had theoretical merit. Future weight loss competitions should attempt to reduce intervention burden on participants, especially if targeting low SES groups who experience disproportionately poorer access to health care due to cost, lack of transport and lack of childcare [55]. Maximising support to motivate participant retention is important. Incentives offer a promising strategy for encouraging retention in weight loss interventions.

\section{Abbreviations}

ABSI: A Body Shape Index; BMI: body mass index; CVD: cardiovascular disease; NZ: New Zealand; SD: standard deviation; T2D: type 2 diabetes; US: United States; WC: waist circumference

\section{Acknowledgements}

Our thanks go to the community providers who were critical to the trial: Ngati Hine Hauora Trust, Te Wakahuia Manawatu Trust and Pacific Heartbeat of the Heart Foundation; and Mea (http://we-are-mea.com/) for website design. Dr. Glover's affiliation is listed as Massey University which was her place of work at the time of the study.

\section{Funding}

This work was supported by the New Zealand Ministry of Health as part of its Diabetes Risk Reduction and Support package. The Ministry of Health had no role in the design of the study; collection, analysis, or interpretation of data; nor did they have any input into the writing of the manuscript. BHB and RK are supported by the Health Research Council of New Zealand to perform research of new pathways to obesity prevention and metabolic health. GK was initially supported by a Heart Foundation Fellowship.

\section{Availability of data and materials}

Participant consent did not include consent for posting the data in an online repository. The datasets used and/or analysed during the current study are available from the corresponding author on reasonable request.

\section{Authors' contributions}

MG conceived of the analysis, MN conducted the analysis, MN and MG wrote the first draft of the paper, AW provided supervisory support and advice to MN and contributed to early drafts of the paper. MS provided statistical advice. MG, HMCR, JS, RK, MFT and BHB contributed to the design of the overall study and intervention and helped obtain funding. MG and JS were responsible for daily delivery. All authors contributed to the writing of the paper and all authors read and approved the final manuscript.

\section{Ethics approval and consent to participate}

This study was conducted according to the guidelines laid down in the Declaration of Helsinki and all procedures involving human subjects/patients were approved by the Northern B Health and Disability Ethics Committee (16/NTB/101) on 5 July 2016. Written informed consent was obtained from all participants.
Consent for publication

Not applicable.

\section{Competing interests}

The authors declare that they have no competing interests.

\section{Publisher's Note}

Springer Nature remains neutral with regard to jurisdictional claims in published maps and institutional affiliations.

\section{Author details}

${ }^{1}$ School of Health Sciences, College of Health, Massey University, PO Box 89186, Torbay, Auckland 0742, New Zealand. ${ }^{2}$ Health and Society, Wageningen University \& Research, Wageningen, The Netherlands. ${ }^{3}$ Dragon Institute, Auckland, New Zealand. ${ }^{4}$ School of Sport, Exercise and Nutrition, College of Health, Massey University, Auckland, New Zealand. ${ }^{5}$ Pacific Heartbeat, Heart Foundation, Auckland, New Zealand. ${ }^{6}$ Environmental Health Indicators Programme, Centre for Public Health Research, Massey University, Wellington, New Zealand.

Received: 1 June 2018 Accepted: 3 January 2019

Published online: 04 March 2019

\section{References}

1. Uzogara SG. Obesity epidemic, Medical and Quality of Life Consequences: A Review. Int J Public Health Res. 2017;5:1.

2. Parackal S, Stewart J, Ho E. Exploring reasons for ethnic disparities in dietand lifestyle-related chronic disease for Asian sub-groups in New Zealand: a scoping exercise. Ethn Health. 2017;22:333-47.

3. Ministry of Health. Annual Update of Key Results 2014/15: New Zealand health survey. Wellington: Ministry of Health; 2015.

4. Teng AM, Blakely T, Baker MG, Sarfati D. The contribution of helicobacter pylori to excess gastric cancer in indigenous and Pacific men: a birth cohort estimate. Gastric Cancer. 2017;20(4):752-5.

5. Chan W, Jackson G, Wright C, Orr-Walker B, Drury P, Boswell DR, et al. The future of population registers: linking routine health datasets to assess a population's current glycaemic status for quality improvement. BMJ Open. 2014;4:e003975

6. Ministry of Health. Cardiovascular disease. Mortality Collection Data Set (MORT). 2015. [Online]. Available: http://www.health.govt.nz/our-work/ populations/maori-health/tatau-kahukura-maori-health-statistics/nga-manahauora-tutohu-health-status-indicators/cardiovascular-disease.

7. U.S. Department of Health and Human Services [DHSS] \& National Institutes of Health $(\mathrm{NIH})$. Strategic plan for $\mathrm{NIH}$ obesity research. A report of the $\mathrm{NIH}$ Obesity Research Task Force. 2013.

8. US Task Force on Preventive Services [USTFPS]. Methods used for reviewing evidence and linking evidence to recommendations, in The guide to community preventive services: What works to promote health? New York: Oxford University Press; 2005. p. 431-48.

9. Jensen M, Ryan D, Donato K, Apovian C, Ard J, Yanovski S. Guidelines (2013) for managing overweight and obesity in adults. Obesity. 2014;22(S2):S1-S410.

10. Johnson SE. Pragmatic implementation trials: understanding the integrated research-practice partnership approach to lifestyle obesity management across a transforming health system. Doctoral dissertation. Virginia: Virginia Polytechnic Institute and State University; 2017.

11. Diabetes Prevention Program (DPP) Research Group. The diabetes prevention program (DPP) description of lifestyle intervention. Diabetes Care. 2002;25(12):2165-71.

12. Quirke T, Edwards D, Brewerton M. Health and Pacific peoples in New Zealand Pacific progress. New Zealand: Statistics New Zealand; 2011. [Online]. http://www.stats.govt.nz/browse_for_stats/people_and_ communities/pacific_peoples/pacific-progress-health.aspx

13. Robson B, Harris R. Hauora: Mãori Standards of Health IV. A study of the years 2000-2005. Wellington: Te Rōpū Rangahau Hauora a Eru Pōmare; 2007.

14. Kolahdooz F, Sadeghirad B, Corriveau A, Sharma S. Prevalence of overweight and obesity among indigenous populations in Canada: a systematic review and meta-analysis. Crit Rev Food Sci Nutr. 2017;57(7):1316-27.

15. Rice K, Te Hiwi B, Zwarenstein M, Lavallee B, Barre DE, Harris SD. Best practices for the prevention and Management of Diabetes and ObesityRelated Chronic Disease among indigenous peoples in Canada: a review. Can J Diabetes. 2016;40(3):216-25. 
16. Schramm AM, DiDonato KL, May JR, Hartwig DM. Implementation of a financially incentivized weight loss competition into an already established employee wellness program. Inov Pharm. 2014;5(3):1-12.

17. Wing RR, Pinto AM, Crane MM, Kumar R, Weinberg BM, Gorin AA. A statewide intervention reduces BMI in adults: shape up Rhode Island results. Obesity. 2009;17(5):991-5.

18. Glover M, Kira A, Kira G, McRobbie H, Breier BH, Kruger R, et al. An innovative team-based weightloss competition to reduce cardiovascular and diabetes risk among Māori and Pacific people: rationale and method for the study and its evaluation. BMC Nutrition. 2017;3(78):1-9.

19. Glover $M$, Breier BH, Bauld L. Could vaping be a new weapon in the battle of the bulge? Nicotine Tob Res. 2016:1-5. https://doi.org/10.1093/ntr/ntw278.

20. Rossi PH, Lipsey MW, Freeman HE. Evaluation: A systematic approach. California: Sage publications; 2003.

21. Pulotu-Endemann FK. Fonofale model; 2009.

22. Ministry of Health. Eating and Activity Guidelines for New Zealand Adults. Wellington: Ministry of Health; 2015.

23. Ministry of Health. Tier 1 statistics 2016/17: New Zealand health survey, vol. 2017. Wellington: Ministry of Health.

24. Harting J, van Assema P. Exploring the conceptualization of program theories in Dutch community programs: a multiple case study. Health Promot Int. 2011;26(1):23-36.

25. Patton MQ. Utilization-focused evaluation. California: Sage Publications; 2008.

26. Bowen GA. Document analysis as a qualitative research method. Qual Res J. 2009;9(2):27-40

27. Abbott ML. Understanding educational statistics using Microsoft excel and SPSS; 2014.

28. Malara M, Kęska A, Tkaczyk J, Lutosławska G. Body shape index versus body mass index as correlates of health risk in young healthy sedentary men. J Transl Med. 2015;13:75

29. Krakauer NY, Krakauer JC. A new body shape index predicts mortality hazard independently of body mass index. PlosOne. 2012;7:e39504.

30. Duncan MJ, Mota J, Vale S, Santos MP, Ribeiro JC. Associations between body mass index, waist circumference and body shape index with resting blood pressure in Portuguese adolescents. Ann Hum Biol. 2013;40(2):163-7.

31. Zuur AF, leno EN, Elphick CS. A protocol for data exploration to avoid common statistical problems. Methods Ecol Evol. 2010;1:3-14.

32. Terranova CO, Brakenridge CL, Lawler SP, Eakin EG, Reeves MM. Effectiveness of lifestyle-based weight loss interventions for adults with type 2 diabetes: a systematic review and meta-analysis. Diabetes Obes Metab. 2015;17(4):371-8.

33. Ministry of Health. New Zealand Health Strategy: Future direction. Wellington: Minister of Health; 2016.

34. Fleig L, Gardner B, Keller J, Lippke S, Pomp S, Wiedemann AU. What contributes to action plan enactment? Examining characteristics of physical activity plans. Br J Health Psychol. 2017;22(4):940-57.

35. Shin DW, Yun JM, Shin JH, Kwon H, Min HY, Joh HK, et al. Enhancing physical activity and reducing obesity through smartcare and financial incentives: a pilot randomized trial. Obesity. 2017;25(2):302-10.

36. Moroshko I, Brennan L, O'Brien P. Predictors of dropout in weight loss interventions: a systematic review of the literature. Obes Rev. 2011;12(11):912-34.

37. Aguiar EJ, Morgan PJ, Collins CE, Plotnikoff RC, Young MD, Callister R. Process evaluation of the type 2 diabetes mellitus PULSE program randomized controlled trial: recruitment, engagement, and overall satisfaction. Am J Mens Health. 2017;11(4):1055-68.

38. Haines PS, Hama MY, Guilkey DK, Popkin BM. Weekend eating in the United States is linked with greater energy, fat, and alcohol intake. Obesity. 2003:11(8):945-9.

39. de Castro JM. Age-related changes in the social, psychological, and temporal influences on food intake in free-living healthy, adult humans. J Gerontol A Biol Sci Med Sci. 2002;57(6):M368-77.

40. Matthews CE, Ainsworth BE, Thompson RW, Bassett D. Sources of variance in daily physical activity levels as measured by an accelerometer. Med Sci Sports Exerc. 2002;34(8):1376-81.

41. Stenhouse J. Religion and society - Towards a more secular society, 1970-21st century': Te Ara - the Encyclopedia of New Zealand; 2017 [Online]. http://www.TeAra.govt.nz/en/religion-and-society/page-8. Accessed 8 Dec 2017

42. Vartanian LR, Novak SA. Internalized societal attitudes moderate the impact of weight stigma on avoidance of exercise. Obesity. 2011;19(4):757-62.

43. Mayor S. Cash for cutting calories: are financial incentives the way forward for weight loss? Lancet Diabetes Endocrinol. 2013;1(1):e5-6.
44. Strohacker K, Galarraga O, Williams DM. The impact of incentives on exercise behavior: a systematic review of randomized controlled trials. Ann Behav Med. 2014;48(1):92-9.

45. Hammarström A, Wiklund AF, Lindahl B, Larsson C, Ahlgren C. Experiences of barriers and facilitators to weight-loss in a diet intervention - a qualitative study of women in Northern Sweden. BMC Womens Health. 2014;14(59):1-10.

46. Look AHEAD Research Group. Eight-year weight losses with an intensive lifestyle intervention: the look AHEAD study. Obesity. 2014;22(1):5-13.

47. Carels RA, Cacciapaglia HM, Douglass OM, Rydin S, O'Brien WH. The early identification of poor treatment outcome in a women's weight loss program. Eat Behav. 2003;4:265-82.

48. BinDhim NF, Trevena $L$. There's an app for that: a guide for healthcare practitioners and researchers on smartphone technology. Online J Public Health Inform. 2017;2:e218.

49. van de Mortel TF. Faking it: social desirability response bias in self-report research. Australian J Adv Nurs. 2008;25(4):40.

50. Johnston V, Liberato $S$, Thomas D. Incentives for preventing smoking in children and adolescents, in V. Johnston (Ed.) Cochrane Database of Systematic Reviews. Chichester: Wiley; 2012

51. Burke LE, Wang J, Sevick MA. Self-monitoring in weight loss: a systematic review of the literature. J Am Diet Assoc. 2011;111(1):92-102.

52. Foster GD, Makris AP, Bailer BA. Behavioral treatment of obesity. Am J Clin Nutr. 2005:82:2308-58.

53. Karfopoulou E, Anastasiou CA, Avgeraki E, Kosmidis MH, Yannakoulia M. The role of social support in weight loss maintenance: results from the MedWeight study. J Behav Med. 2016;39(3):511-8.

54. Ryan RM, Deci EL. Self-Determination Theory and the Facilitation of Intrinsic Motivation, Social Development, and Well-Being. American Psychol. 2000; 55(1):68-78.

55. Adler N, Stewart J. Health disparities across the lifespan: meaning, methods, and mechanisms. Ann N Y Acad Sci. 2010;1186(1):5-23.

56. University of Otago and Ministry of Health. A focus on Nutrition: Key findings of the 2008/09. Wellington: New Zealand Adult Nutrition Survey; 2011. [Online]. http://www.health.govt.nz/publication/focus-nutrition-keyfindings-2008-09-nz-adult-nutrition-survey.

57. Butnariu M, Butu A. Chemical composition of vegetables and their products, in handbook of food chemistry. Berlin, Heidelberg: Springer; 2015. p. 627-92.

58. United States Department of Agriculture. A series of systematic reviews on the relationship between dietary patterns and health outcomes. Alexandria: Evidence Analysis Library Division Center for Nutrition Policy and Promotion, US Department of Agriculture; 2014

59. Joint WHO/FAO Expert Consultation on Diet, Nutrition and the Prevention of Chronic Diseases (2002 : Geneva, Switzerland) Diet, nutrition and the prevention of chronic diseases: report of a joint WHO/FAO expert consultation. Geneva; 2002

60. Scottish Government. Scottish government survey: obesity. Edinburgh: Scottish Government; 2011.

61. Brown WJ, Williams L, Ford JH, Ball K, Dobson AJ. Identifying the energy gap: magnitude and determinants of 5-year weight gain in midage women. Obes Res. 2005;13:1431-41.

62. Patel $A V$, Bernstein $L$, Deka $L$, et al. Leisure time spent sitting in relation to total mortality in a prospective cohort of US adults. Am J Epidemiol. 2011;172:419-29.

63. Willett W. Eat, drink, and be healthy: the Harvard Medical School guide to healthy eating. New York: Simon and Schuster; 2011

64. Pereira MA, Kartashov Al, Ebbeling CB, Van Horn L, Slattery ML, Jacobs DR, et al. Fast-food habits, weight gain, and insulin resistance (the CARDIA study): 15-year prospective analysis. Lancet. 2005;365(9453):36-42.

65. Hooper L, Martin N, Abdelhamid A, Davey SG. Reduction in saturated fat for cardiovascular disease (review). Cochrane Database Syst Rev. 2015;6:1-111.

66. Duffey K, Gordon-Larsen P, Jacobs DR, Williams OD, Popkin BM. Differential associations of fast food and restaurant food consumption with 3-y change in body mass index: the coronary artery risk development in Young adults study. Am J Clin Nutr. 2007;85(1):201-8.

67. Jaworowska A, Blackham T, Davies IG, Stevenson L. Nutritional challenges and health implications of takeaway and fast food. Nutr Rev. 2013;71(5): 310-8.

68. Te Morenga L, Mallard S, Mann J. Dietary sugars and body weight: systematic review and meta-analyses of randomised controlled trials and cohort studies. BMJ 2013;346:e7492. p. 1-25.

69. Owen $N$, Sugiyama T, Eakin $E$, et al. Adults' sedentary behavior: determinants and interventions. Am J Prev Med. 2011;41(2):189-96. 
70. Van Dyck D, Cerin E, Conway TL, De Bourdeaudhuij I, Owen N, Kerr J, et al. Associations between perceived neighborhood environmental attributes and adults' sedentary behavior: findings from the USA, Australia and Belgium. Soc Sci Med. 2012;74(9):1375-84.

71. Buckley J, Hedge A, Yates T, Copeland R, Loosemore M, Hamer M, et al. The sedentary office: a growing case for change towards better health and productivity. Expert statement commissioned by Public Health England and the Active Working Community Interest Company. Br J Sports Med. 2015;49(21):1357-62.

72. Kabat-Zinn J. Mindfulness-based interventions in context: past, present, and future. Clin Psychol Sci Pract. 2006;10(2):144-56.

73. Jordan $\mathrm{CH}$, Wang W, Donatoni L, Meier BP. Mindful eating: Trait and state mindfulness predict healthier eating behavior. Personal Individ Differ. 2014; 68:107-11.

Ready to submit your research? Choose BMC and benefit from:

- fast, convenient online submission

- thorough peer review by experienced researchers in your field

- rapid publication on acceptance

- support for research data, including large and complex data types

- gold Open Access which fosters wider collaboration and increased citations

- maximum visibility for your research: over $100 \mathrm{M}$ website views per year

At $\mathrm{BMC}$, research is always in progress.

Learn more biomedcentral.com/submissions 